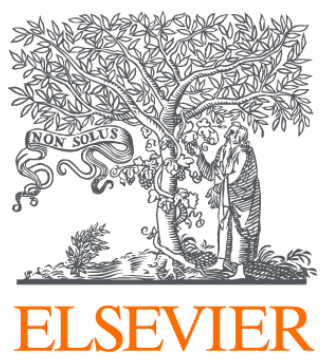

Since January 2020 Elsevier has created a COVID-19 resource centre with free information in English and Mandarin on the novel coronavirus COVID-

19. The COVID-19 resource centre is hosted on Elsevier Connect, the company's public news and information website.

Elsevier hereby grants permission to make all its COVID-19-related research that is available on the COVID-19 resource centre - including this research content - immediately available in PubMed Central and other publicly funded repositories, such as the WHO COVID database with rights for unrestricted research re-use and analyses in any form or by any means with acknowledgement of the original source. These permissions are granted for free by Elsevier for as long as the COVID-19 resource centre remains active. 
News and Views

\section{Journal Roundup}

There has been a sharp increase in the number of cases of Middle East respiratory syndrome coronavirus (MERS-CoV) reported in recent months, with more than 418 of the 614 cases reported in the past two months according to a Lancet commentary. ${ }^{1}$ This has prompted renewed discussion in the Lancet about how best to protect healthcare workers at risk from MERS-CoV. ${ }^{2}$ The guidance from the US Centers for Disease Control and Public Health England is clear: healthcare workers should wear gloves, gowns, N95/FFP3 respiratory, and perform hand hygiene. ${ }^{2}$ However, evidence from severe acute respiratory syndrome coronavirus (SARS-CoV) suggests that compliance with these simple procedures may be lower than expected. ${ }^{3}$ In this study, even when caring for patients known to be infected with SARS, $<30 \%$ of healthcare workers selfreported that they wore a mask, gloves, gown, and washed their hands as they should have done. Most importantly, none of the healthcare workers who complied with all four measures became infected.

The BMJ published a short reflection on the World Health Organization report on antibiotic resistance, with high rates of resistance reported from many parts of the world. ${ }^{4}$ JAMA published a viewpoint outlining the perpetual challenge of antibiotics, focused on the emergence of carbapenemresistant Enterobacteriaceae (CRE) and presenting a rather depressing scenario of a war that we cannot win. ${ }^{5}$ Meanwhile, in JAMA Internal Medicine, a thoughtful article discusses why antibiotic over-use continues in hospitals. ${ }^{6}$ Simply telling doctors to reduce prescribing will not work: effective strategies must promote individual and societal benefits.

Clinical Infectious Diseases has published two important updates on faecal microbiota transplantation (FMT) for recurrent Clostridium difficile infection (CDI). FMT has already been shown to be substantially more effective than vancomycin for treating recurrent CDI, and Konijeti et al. show that it is also the most cost-effective option. ${ }^{7,8}$ The source of donor stool for FMT is an area of controversy and concern. Most studies have used fresh stool from related donors. A small randomized controlled trial showed that frozen stool from unrelated donors is also effective in treating recurrent CDI. ${ }^{9}$ The bottom line is that - fresh or frozen, yours or somebody else's, stool bank or laboratory donor, nasogastric tube or enema - FMT works for recurrent CDI.

Few retrospective observational studies are published in the Lancet, but this is a good one: evaluating the impact of nurse staffing and education on mortality in nine European countries. ${ }^{10}$ Increasing nurses' workload by $1 \%$ increased mortality by $7 \%$, whereas every $10 \%$ increase in nurses with a bachelor's degree decreased mortality by $7 \%$. It seems that busy, poorly qualified nurses are a risk to patients!

The idea of switching from empiric antibiotics to a tailored antibiotic based on bacterial susceptibility testing is familiar. However, a Lancet ID review considers individualized antibiotic dosing for critically ill patients. ${ }^{11}$ The idea is that by accounting for changes in the patient's physiological characteristics and the degree of bacterial susceptibility to the antibiotic, an individualized dose can be modelled to maximize effectiveness.

CA-MRSA is well established in some parts of the USA. An American Journal of Infection Control study sampled inanimate surfaces in fire stations in Washington state, finding MRSA on $8 \%$ of 653 samples. ${ }^{12}$ More than a third of the 33 fire stations reported staff with MRSA requiring medical care. It is difficult to know why CA-MRSA has become established in some parts of the USA, but is relatively rare in much of Europe. ${ }^{13}$

Many children of school age love nothing more than 'taking a sickie' (using the 'thermometer on the light bulb trick', among others). A large community-based hand hygiene intervention in Spanish school-aged children showed a significant impact in reducing upper respiratory tract and gastrointestinal infections, and cut down the number of genuine sickies! ${ }^{14}$

An interesting outbreak of CRE in Ireland reported in the Journal of Hospital Infection comprised the co-circulation of two distinct clones of OXA-48 producing Klebsiella pneumoniae. ${ }^{15}$ The clones seemed to be circulating separately among medical and surgical patients. It is tempting to speculate that the OXA-48-carbapenemase was shared between the two clones, representing an 'outbreak of resistance'. ${ }^{16}$

Infection Control and Hospital Epidemiology published two updated guidelines for surgical site infection and CDI. ${ }^{17,18}$ The CDI guideline upholds the surprising recommendation for soap and water or alcohol for hand hygiene in 'routine/ endemic' settings, and soap and water only in 'endemic/hyperendemic settings'. This is a complex message to convey, and does not sit well with laboratory data showing inferior performance of alcohol for hand hygiene for $C$. difficile spores. ${ }^{19}$

Another Infection Control and Hospital Epidemiology article identified 'optimum outlier' cleaners, who performed rapidly and effectively. ${ }^{20}$ These individuals can be used as role models for others. The use of 'optimum outlier' rests more easily than 'positive deviant', which just sounds bad!

The USA is gradually moving towards a 'bare below the elbow' approach, but not without considerable resistance according to a survey in Infection Control and Hospital Epidemiology. ${ }^{21}$ This issue seems to evoke surprisingly strong 
opinions from healthcare workers, who can be somewhat image conscious. The experience from the UK shows that 'bare below the elbow' can be successfully implemented, which, on balance, makes sense.

Healthcare professionals can struggle to see the world from the patient's viewpoint - until they become one themselves. A harrowing patient story from an infection control nurse in the Journal of Infection Prevention can help us to understand the patient's viewpoint: 'You may wonder why someone such as myself did not shout louder about the standards of care and treatment but until you have been in this vulnerable situation yourself it is difficult to appreciate just how frightening it is. ${ }^{22}$

The advent of smartphones has led to a huge number of 'mHealth' apps, designed to support healthcare professionals. ${ }^{23}$ The US Food and Drug Administration (FDA) recently announced that apps acting as medical devices, or as accessories to medical devices, will require FDA approval. Regulation is important, but, much like a 'wiki' website (developed through a community of users), successful apps are likely to be accurate, otherwise they would not become successful!

In terms of conferences, the Society for Healthcare Epidemiology of America (SHEA) and Healthcare Infection Society (HIS)/Infection Prevention Society (IPS) Spring Meetings, the 24th European Congress of Clinical Microbiology and Infectious Diseases (ECCMID), and the APIC (Association for Professionals in Infection Control and Epidemiology) Annual Conference have been and gone. The abstracts from ECCMID are available at www.eccmid.org, and the APIC abstracts are published in the American Journal of Infection Control. ${ }^{24}$

And finally, we all know that many restaurant-associated foodborne outbreaks go undetected; causing foodborne outbreaks hardly makes for a popular restaurant. It turns out that an online customer review website (Yelp) was a useful way to identify cases that were not reported during an outbreak investigation, according to an MMWR study. ${ }^{25}$ Customer review websites might be a useful and previously unrecognized tool in outbreak detection and investigation.

\section{References}

1. Holmes D. MERS-CoV enigma deepens as reported cases surge. Lancet 2014;383:1793.

2. Zumla A, Hui DS. Infection control and MERS-CoV in health-care workers. Lancet 2014;383(9932):1869-1871.

3. Seto WH, Tsang D, Yung RW, et al. Effectiveness of precautions against droplets and contact in prevention of nosocomial transmission of severe acute respiratory syndrome (SARS). Lancet 2003;361:1519-1520.

4. Gulland A. Antimicrobial resistance is now widespread, warns WHO. BMJ 2014;348:g3062.

5. Fauci AS, Marston ID. The perpetual challenge of antimicrobial resistance. JAMA 2014;311:1853-1854.

6. Flanders SA, Saint S. Why does antimicrobial overuse in hospitalized patients persist? JAMA Intern Med 2014;174:661-662.

7. van Nood E, Dijkgraaf MG, Keller JJ. Duodenal infusion of feces for recurrent Clostridium difficile. N Engl J Med 2013;368:2145.

8. Konijeti GG, Sauk J, Shrime MG, Gupta M, Ananthakrishnan AN. Cost-effectiveness of competing strategies for management of recurrent Clostridium difficile infection: a decision analysis. Clin Infect Dis 2014;58:1507-1514.

9. Youngster I, Sauk J, Pindar C, et al. Fecal microbiota transplant for relapsing Clostridium difficile infection using a frozen inoculum from unrelated donors: a randomized, open-label, controlled pilot study. Clin Infect Dis 2014;58:1515-1522.

10. Aiken LH, Sloane DM, Bruyneel L, et al. Nurse staffing and education and hospital mortality in nine European countries: a retrospective observational study. Lancet 2014;383:1824-1830.

11. Roberts JA, Abdul-Aziz MH, Lipman J, et al. Individualised antibiotic dosing for patients who are critically ill: challenges and potential solutions. Lancet Infect Dis 2014;14:498-509.

12. Roberts MC, No DB. Environment surface sampling in 33 Washington State fire stations for methicillin-resistant and methicillinsusceptible Staphylococcus aureus. Am J Infect Control 2014;42:591-596.

13. Otter JA, French GL. Molecular epidemiology of communityassociated meticillin-resistant Staphylococcus aureus in Europe. Lancet Infect Dis 2010;10:227-239.

14. Azor-Martinez E, Gonzalez-Jimenez Y, Seijas-Vazquez ML, et al. The impact of common infections on school absenteeism during an academic year. Am J Infect Control 2014;42:632-637.

15. Wrenn C, O'Brien D, Keating D, et al. Investigation of the first outbreak of OXA-48-producing Klebsiella pneumoniae in Ireland. $J$ Hosp Infect 2014;87:41-46.

16. Vlek AL, Cooper BS, Kypraios T, Cox A, Edgeworth JD, Auguet OT. Clustering of antimicrobial resistance outbreaks across bacterial species in the intensive care unit. Clin Infect Dis 2013;57:65-76.

17. Anderson DJ, Podgorny K, Berrios-Torres SI, et al. Strategies to prevent surgical site infections in acute care hospitals: 2014 update. Infect Control Hosp Epidemiol 2014;35:605-627.

18. Dubberke ER, Carling P, Carrico R, et al. Strategies to prevent Clostridium difficile infections in acute care hospitals: 2014 update. Infect Control Hosp Epidemiol 2014;35:628-645.

19. Kundrapu S, Sunkesula V, Jury I, Deshpande A, Donskey CJ. A randomized trial of soap and water hand wash versus alcohol hand rub for removal of Clostridium difficile spores from hands of patients. Infect Control Hosp Epidemiol 2014;35:204-206.

20. Rupp ME, Huerta T, Cavalieri RJ, et al. Optimum outlier model for potential improvement of environmental cleaning and disinfection. Infect Control Hosp Epidemiol 2014;35:721-723.

21. Pellerin J, Bearman G, Sorah J, Sanogo K, Stevens M, Edmond MB. Healthcare worker perception of bare below the elbows: readiness for change? Infect Control Hosp Epidemiol 2014;35: 740-742.

22. Horsfield C. A personal experience of care and the lack of it. J Infect Prevent 2014;15:82-83.

23. Powell AC, Landman AB, Bates DW. In search of a few good apps. JAMA 2014;311:1851-1852.

24. $41^{\text {st }}$ Annual Conference Abstracts, APIC 2014, Anaheim, CA, June 2014. Am J Infect Control 2014;42:S1-S188.

25. Harrison C, Jorder M, Stern $H$, et al. Using online reviews by restaurant patrons to identify unreported cases of foodborne illness - New York City, 2012-2013. Morb Mortal Wkly Rep 2014;63:441-445.

J.A. Otter

King's College London, and Guy's and St Thomas' Hospital NHS Foundation Trust London, UK

E-mail address: jonathan.otter@kcl.ac.uk Available online 24 June 2014 